\title{
A Polyherbal Indian System of Medicine (Ayush) Preparation for Optimization of Glycemic Control in Newly Diagnosed Type 2 Diabetes and Prediabetes; A Multicenter, Randomised, Double-Blind, Placebo- Controlled Trial
}

\author{
Alben Sigamani ${ }^{1 *}$, Sanjaya Chauhan ${ }^{1}$, Vikneswaran ${ }^{1}$, Sindhu $N^{1}$, Anju Joseph ${ }^{1}$, Arun Kumar ${ }^{1}$, Padma KG ${ }^{1}$, Sandeep Kumar \\ Gupta $^{2}$, Shashank Tiwari ${ }^{2}$, Subramanian Kannan ${ }^{3}$, Haleh Roohi ${ }^{4}$, Leva Samimi ${ }^{4}$, Prathipati Philip ${ }^{5}$ and Chandrakala Pidathala ${ }^{5}$ \\ ${ }^{1}$ Department of Clinical Research, Narayana Hrudayalaya Limited, Karnataka, India \\ ${ }^{2}$ KRM Hospital and Research Centre, Lucknow, Uttar Pradesh, India \\ ${ }^{3}$ Department of Endocrinology, Mazumdar Shaw Medical Center, Narayana Hrudayalaya Limited, Karnataka, India \\ ${ }^{4}$ Bahai Institute for Higher Education, Iran \\ ${ }^{5}$ Organic India Pvt Limited, Uttar Pradesh, India
}

${ }^{*}$ Corresponding Author: Dr. Alben Sigamani, Mazumdar Shaw Medical Centre, Narayana Health City; Tel : +91-8884431444;

E-mail: alben.sigamani.dr@narayanahealth.org

Received: January 07, 2019; Accepted: January 19, 2019; Published: February 09, 2019;

\begin{abstract}
Background: Current therapeutics do not provide optimized care in early stage type 2 diabetes and there is no established treatment for prediabetes. We did a randomised trial to assess the efficacy and safety of a popular Ayush product, Sugar Balance® (sugar balance) in patients with newly diagnosed type 2 diabetes and prediabetes.

Methods: In this multicentre, double blind placebo-controlled trial, we randomly assigned (1:1) eligible participants, 30 years of age or older, of either gender and diagnosed with type 2 diabetes ( $\mathrm{HbA} 1 \mathrm{c} \geq 6.5 \%$ ) or prediabetes (FPG $\geq 5.6 \mathrm{mmol} / \mathrm{L}$ ). We used computer-generated ramdomisation, stratified by type of diagnosis (prediabetes or diabetes). Active recipients were to receive $250 \mathrm{mg}$ capsules containing 3 Organic certified whole herbs: Coccinia indica, Bougainvillea spectabilis and Madagascar periwinkle (sadabahar). The recommended dose was 2 capsules twice daily. The primary outcome was $\geq 0.5 \%$ reduction in $\mathrm{HbA}_{1 c}$ for type 2 diabetes subjects and an increased incidence of normalization in impaired fasting blood glucose for prediabetes subjects at 6 months after randomization. The primary analysis included all subjects who received the allocated intervention and had 1 follow up visit after randomisation. All subjects received standard life style recommendations for diet and exercise. Type 2 diabetes subjects were allowed to be on biguanides (metformin) of their choice. This trial is registered with ClinicalTrials.gov, number NCT02866539 and clinical trials registry of India, number CTRI/2016/11/007435, and is completed.
\end{abstract}

Findings: Between December $14^{\text {th }} 2016$ and $28^{\text {th }}$ August 2017, 122 subjects were randomly assigned to active sugar balance (n=61) or matching placebo $(n=61)$, of whom one subject (assigned to placebo) did not receive the allocated intervention. All follow up was completed on $16^{\text {th }}$ December 2017 . At 6 months type 2 diabetes subjects allocated to active arm had a mean reduction of $\mathrm{HbA}_{1 \mathrm{c}}$ of $-0.52 \%$ versus $-0.43 \%$ among placebo arm (difference of $-0.09 \%$ $95 \%$ CI $-0.1705--0.0095) .13(52 \%)$ versus $4(15.4 \%)$ prediabetes subjects receiving the polyherbal achieved normalization of impaired fasting glycaemia $(<100 \mathrm{mg} / \mathrm{dl}$ ) (difference of $36.6 \% 95 \%$ CI 10.683 - 56.805). None of the study participants experienced significant hypoglycemia or significant changes in their safety clinical biochemistry parameters on therapy.

Conclusions: Sugar Balance promises to be effective and safe supplement for type 2 diabetes subjects to achieve a better optimization of $\mathrm{HbA}_{1 \mathrm{c}}$ when taken along with standard dose of metformin and for prediabetes subjects to achieve their target fasting blood sugars with diet and exercise.

Keywords: Ayush, Polyherb, Organic Sugar Balance, Prediabetes, Type 2 Diabetes Mellitus 
Alben Sigamani (2019) A Polyherbal Indian System of Medicine (Ayush) Preparation for Optimization of Glycemic Control in Newly Diagnosed Type 2 Diabetes and Prediabetes; A Multicenter, Randomised, Double-Blind, Placebo-Controlled Trial

\section{Introduction}

Diabetes mellitus is a non-communicable disease of rising concern in global health. In 2017, more than 425 million people across the globe were diagnosed with diabetes and an additional 350 million with prediabetes [1]. The disease contributes to $10.7 \%$ of global deaths [2] and 33 million years lived with disability (YLD) [3]. 77\% of these patients live in low- and middle-income countries and have limited access to biomedical health care [1]. India is one of the countries with largest diabetes population [4] and should explore locally available alternate Ayush based treatments to expand access to care.

A recent study suggests that if epidemiological trends continue, achieving the global target of preventing the rise in diabetes patients has a probability of $<50 \%$ in most of the countries including India [5]. Prevalence of prediabetes is a major threat in India and there are no effective therapies proven for normalization of elevated fasting glucose.

High-quality, low-cost solutions adapted to the local context are critical to addressing the current crisis. Herein we examine the effectiveness of a polyherbal medication, based on the ancient Indian practice of Ayurveda, in the reduction of hyperglycemia in patients with newly diagnosed type 2 diabetes or prediabetes and at two multispecialty hospitals in India.

Holistic medicine is gaining more importance in the treatment of chronic conditions. It is trying to prevent the disease and better the quality of life and health by connecting body, mind and spirit [6]. Ayurveda encourages the practice of emphasizing harmony in the body and cleansing the body of substances that can cause disease [7].

Nevertheless, the most significant reduction in diabetes incidence has been achieved with diet and exercise [8]. Moreover, since Ayurveda-Indian ancient medical traditions- is working on human health by a combination of knowledge, practice and medicine [6].

The present study tested the effectiveness of a polyherbal medicine through a randomized double blinded placebo controlled clinical trial to determine its efficacy and safety in patients with newly diagnosed type 2 diabetes or having laboratory confirmed prediabetes.

\section{Methods}

\section{Study Design and Participants}

This was a double-blind, two-arm, multicentre placebo controlled randomized trial two sites in India; Mazumdar Shaw Medical Centre Bangalore and KRM Hospital, Lucknow. The trial was designed by Department of Clinical Research at Narayana Health, Bangalore. Ramdomisation support was offered by the Department of Biostatistics at St John's Medical College and the statistical analysis plan was further verified by data scientists at Boston Children's Hospital, Boston, MA. The trial participants were randomised under 2 strata based upon their diagnosis; prediabetes or diabetes.

Eligible participants both male and non-pregnant female subjects, 30 years of age or older diagnosed with prediabetes or Type II diabetes by one of four methods: fasting glycaemia $>6.9 \mathrm{mmol} / \mathrm{L}$, or a 2 hour post-prandial glycaemia $>11.1 \mathrm{mmol} / \mathrm{L}$ post 2 hour oral glucose tolerance test, or a glycosylated hemoglobin (HbA1c) $\geq 6.5 \%$, or patients with an episode of classic symptoms of hyperglycaemia or hyperglycaemic crisis and a single random glycaemia of $>11.1 \mathrm{mmol} / \mathrm{L}$ in the last 12 months were included .

Eligible participants were excluded if they reported a history of diabetes onset more than 24 months from the date of randomization or reported treatment with any oral hypoglycemic agents (other than Metformin) or insulin, or with any history suggestive of microvascular or macrovascular disease. Additional exclusion criteria included impaired renal function defined as eGFR less than $60 \mathrm{ml} / \mathrm{min} / 1.73 \mathrm{~m} 2$, blood pressure fluctuations exceeding $10 \mathrm{mmHg}$ on two subsequent clinic visits or known history of hypotension or bradycardia in last 6 months or taking 2 or more antihypertensive medications regularly in the last 6 weeks.

Additionally, women of childbearing age who were unable to use any form of contraception, and any participant participating in another clinical trial with an active intervention or drug or device within the last 60 days, any current or former employees of Organic India Company which manufactures the polyherbal medicine, and any subject refusing consent or unable to commit to treatment adherence were excluded.

\section{Ethical Consideration}

This study was approved by the institute ethics committee at Mazumdar Shaw Medical Center (approval number NHH/AEC_ RC_2016-078(B) and at KRM Hospital, Lucknow (approval number IEC/02/19/17). The study was conducted in accordance with the International Conference on Harmonization guidelines for Good Clinical Practice (ICH E6); The Code of Federal Regulations on the Protection of Human Subjects (45 CFR Part 46); and The AYUSH Guidelines for Good Clinical Practices. Written informed consent was obtained from all the participants before entry in the study. All potential participants were given a study information sheet and were informed about the protocol procedures, the frequency of follow up and total study duration. All personnel involved in the conduct of this study completed human subject's protection training.

\section{Randomization and Masking}

All eligible subjects were stratified into two groups by block randomization based on the diagnosis of either prediabetes or diabetes. Research personnel randomised participants via a digital randomization phone service at the coordinating center situated at the Department of Clinical Research at Narayana Health, Bangalore, India. Randomization codes were generated by an independent statistician. Packed, blinded medication with a unique number was sent to the recruiting sites. Once randomization was assigned to the treatment or control groups, site personnel received a drug code and issued blinded medications to the patient. The treatment and placebo capsules were identical and packed in identical packaging.

\section{Procedures}

The population for the study was derived from subjects referred to KRM Hospital and Research Centre in Lucknow and Mazumdar Shaw Medical Center of Narayana Health Center. Participants were 
screened for eligibility based on inclusion criteria at executive health checkup clinics, outpatient specialty clinics, and from existing records in the two hospitals. Additionally, caregivers accompanying subjects coming to clinic visit were also invited to participate.

The intervention is a popular polyherbal capsule Sugar Balance ${ }^{\star}$ (sugar balance) which is manufactured by Organic India.The active capsule contains a combination of 3 whole herbs: Coccinia indica, Bougainvillea spectabilis and Madagascar periwinkle (sadabahar) of $250 \mathrm{mg}$ having organic certification (ORG/SC/1310/001378) by Control union. The batch number was VX-262 and medication series 358. All three products were as per the organic category of NPOP-Organic Standard of India (National Programme for Organic Production) and NOP-Organic Standard of US (National Organic Programme).

The placebo capsule contained only starch powder of $250 \mathrm{mg}$, the batch number VX-269 and Medication Series 468. As a standardized approach both the active and placebo products were similar looking Opaque capsules.

Participants were instructed to take two capsules twice a day at a fixed time in the day. Capsules were prescribed to be taken orally after food. There were no diet restrictions, but the subjects had to maintain a diet diary for the entire duration of the study to assist in 24-hour dietary recall. They were stratified as diabetes or prediabetes. All diabetes subjects were allowed to be on standard doses of biganides (metformin) as per clinician choice. All prediabetes subjects were not taking any standard medications for lowering blood sugar but received standard lifestyle recommendations. During the six-month study period, participants had a total of 8 clinical visits during which data were collected: baseline at 0 weeks, follow-up at 2 weeks, 4 weeks, 8 weeks, 12 weeks, 16 weeks, 20 weeks, and at 24 weeks.

All participants were given ADA-guided lifestyle advice with free nutrition counselling at each visit. During the study period, the subjects were called every month with reminders about upcoming follow-up clinic visits.

Laboratory procedures were conducted locally in National Accreditation Board for Laboratories of India (NABL) accredited laboratories for study subjects during their scheduled visits, all outcome measures were collated and sent to the data management center.

\section{Study Endpoints}

A reading of fasting glycaemia of more than $6.9 \mathrm{mmol} / \mathrm{L}$ or an $\mathrm{HbAl}$ c value of more than $6.5 \%$ is the primary criteria for the diagnosis of type 2 diabetes. Prediabetes is defined as fasting glycemia 5.6 to $6.9 \mathrm{mmol} / \mathrm{L}$. The primary outcome for prediabetes was proportion of subjects achieving a target fasting glycemia of $<5.6 \mathrm{mmol} / \mathrm{L}$. Safety parameters considered as any significant $(2 \mathrm{x})$ change in renal function and hepatic function at any of the follow up visits and at end of the study treatment period.

\section{Statistical Analysis}

The main outcome measures, $\mathrm{HbA}_{1 \mathrm{c}}$ and fasting glycemia were measured at baseline, 90 days (12 weeks) and 180 days ( 24 weeks) after randomization. Analysis of study data was done using R software version 3.4.4. A secondary analysis was performed after stratification by diabetes status. We used a two-sample t-test and linear regression model to compare numerical variables between the intervention and control groups. A paired t-test was used to compare within-group variables. A Chi-square test was used for categorical variables. All testing was done at a significance level of alpha $=0.05$.

Data scientists based in Boston children's hospital Boston, MA, prepared the analysis plan, and validated the statistical analysis performed by statisticians of Narayana Hrudayalaya.

The analysis was simultaneously done by 2 independents data scientists from India and Boston and the final results were compared.

Data Management Process and Software Used: The data was collected via electronic data source application. Using an Apple Ipad to capture data offline. The application was designed by CliniOps, Inc based upon the data dictionary created by trial scientific expert committee. The software was validated to ensure the proper functioning of application. The application can be used both offline and online and can be accessed on the Web. Data was entered by authorized and trained clinical trial coordinators only.

All the data was collected real time during each visit on to the CliniOps Trial Application version 94.0(electronic CRF) installed on an Apple Ipad 2 offline and synchronized to a cloud server when connected to the internet.

\section{Results}

Between December 14 $14^{\text {th }}, 2016$ and $28^{\text {th }}$ August 2017, 200 subjects were screened at two hospitals in India. 122 subjects were randomised, but 1 subject withdrew consent from trial without taking any medications. 121 subjects were included in the intention to treat analysis. All follow up was completed on $16^{\text {th }}$ December 2017.

The baseline characteristics were comparable between the subjects who received active versus placebo. The average age of the subjects who took active SB was $46.5( \pm 9.8)$ years, $93.3 \%$ subjects were young $<65$ years of age. $48.3 \%$ (29) were males, $61.6 \%$ (37) individuals were either pita-kapha or kapha-vata prakruti as per the ayurvedic phenotype classification.

Out of 60 subjects in the intervention group, 8 lost to follow up. Among them, 3 subjects were from prediabetic and 5 subjects were diabetic. Of the 61 control subjects, 8 were lost to follow up visit. Out of this, 2 subjects were prediabetic and 6 subjects were diabetic. The trial profile of study subjects is represented in figure 1.

At 6 months type 2 diabetes subjects allocated to active arm had a mean reduction of $\mathrm{HbA}_{1 \mathrm{c}}$ of $-0.52 \%$ versus $-0.43 \%$ among placebo arm (difference of $-0.09 \% 95 \%$ CI $-0.1705--0.0095) .13$ (52\%) versus $4(15.4 \%)$ prediabetes subjects receiving the polyherbal achieved normalization of impaired fasting glycaemia $(<100 \mathrm{mg} / \mathrm{dl}$ ) (difference of $36.6 \% 95 \%$ CI $10.683-56.805$ ). 


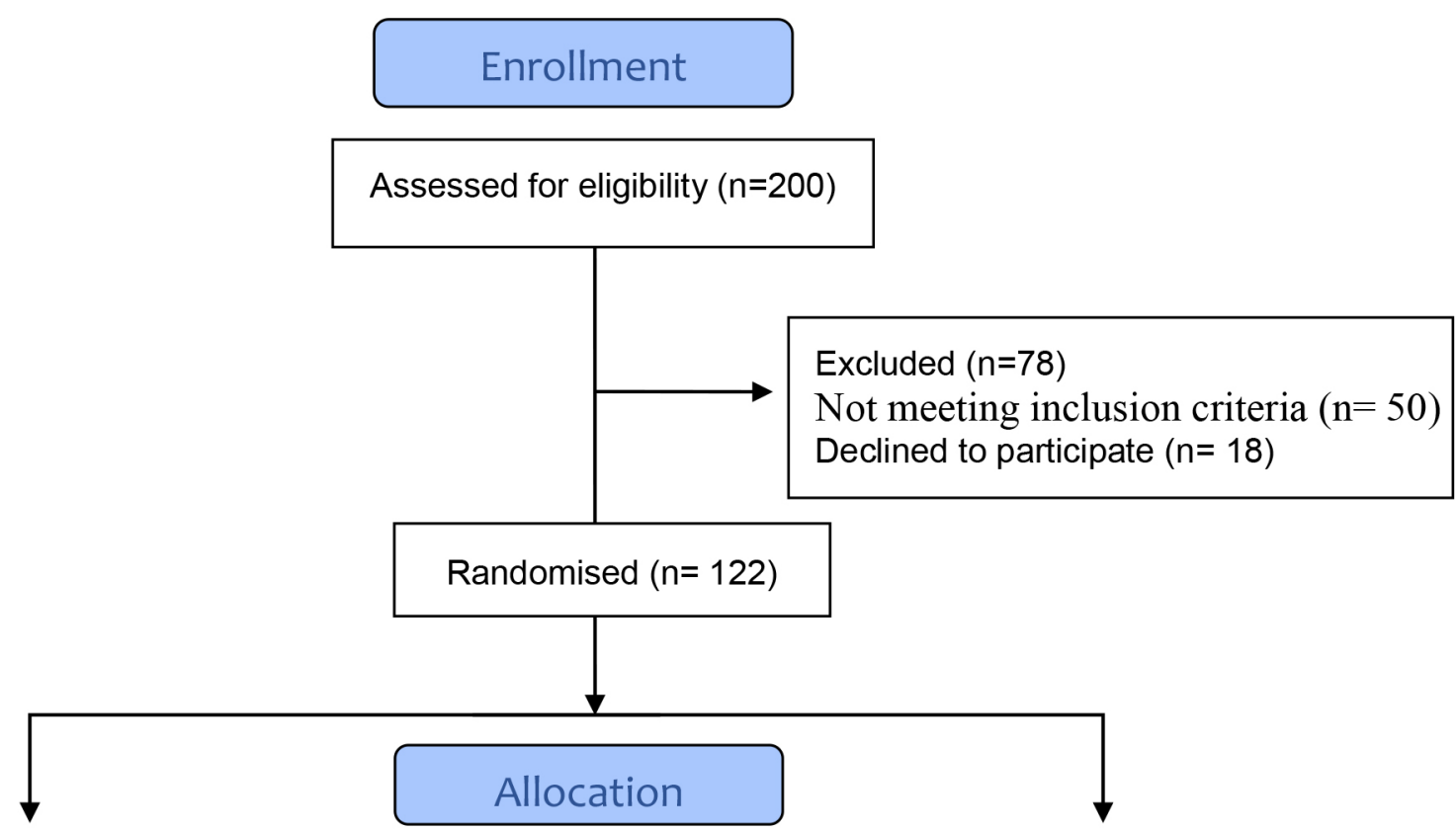

\begin{tabular}{|c|c|c|}
\hline $\begin{array}{l}\text { Allocated to placebo }(n=62) \\
\text { Number of Pre-diabetic }(n=28) \\
\text { Number of Diabetic }(n=33) \\
\text { Did not receive allocated intervention- not } \\
\text { comfortable with lab investigation time }(n=1)\end{array}$ & & $\begin{array}{l}\text { Allocated to intervention }(n=60) \\
\text { Number of Pre-diabetic }(n=28) \\
\text { Number of Diabetic }(n=32)\end{array}$ \\
\hline & Follow-Up & $\downarrow$ \\
\hline $\begin{array}{l}\text { Lost to follow-up at } 1 \text { st visit and } 2^{\text {nd }} \text { visit }(n=04) \\
\text { Lost to follow-up after visit } 3^{\text {rd }} \text { visit }(n=04) \\
\text { Prediabetes (2) and Diabetes (6) }\end{array}$ & & $\begin{array}{l}\text { Lost to follow-up at } 1^{\text {st }} \text { visit and } 2^{\text {nd }} \text { visit }(n=04) \\
\text { Lost to follow-up after visit } 3^{\text {rd }} \text { visit }(n=04) \\
\text { Prediabetes (3) and Diabetes (5) }\end{array}$ \\
\hline$\downarrow$ & Analysis & 1 \\
\hline $\begin{array}{l}\text { Number of subjects completed 6th visit }(n=53) \\
\text { Prediabetes }(n=26) \text { and Diabetes }(n=27)\end{array}$ & & $\begin{array}{l}\text { Number of subjects completed 6th visit }(n=52) \\
\text { Prediabetes }(\mathbf{n}=\mathbf{2 5}) \text { and Diabetes }(\mathbf{n}=\mathbf{2 7})\end{array}$ \\
\hline
\end{tabular}

Figure 1. Participant flow diagram for Sugar Balance. 
Alben Sigamani (2019) A Polyherbal Indian System of Medicine (Ayush) Preparation for Optimization of Glycemic Control in Newly Diagnosed Type 2 Diabetes and Prediabetes; A Multicenter, Randomised, Double-Blind, Placebo-Controlled Trial

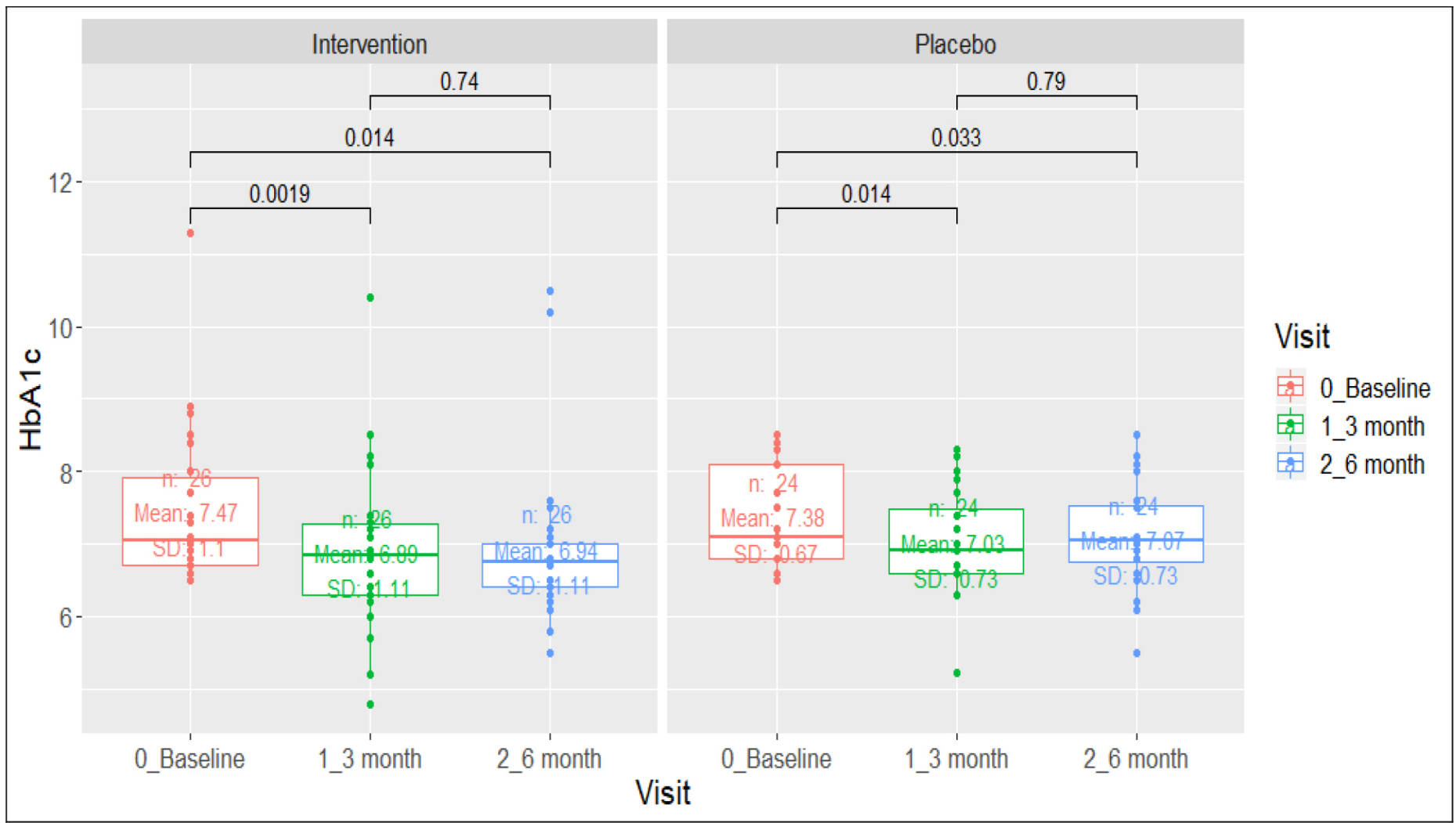

Figure 2. Comparison of $\mathrm{HbA1c}(>6.5 \%)$ in diabetic group.

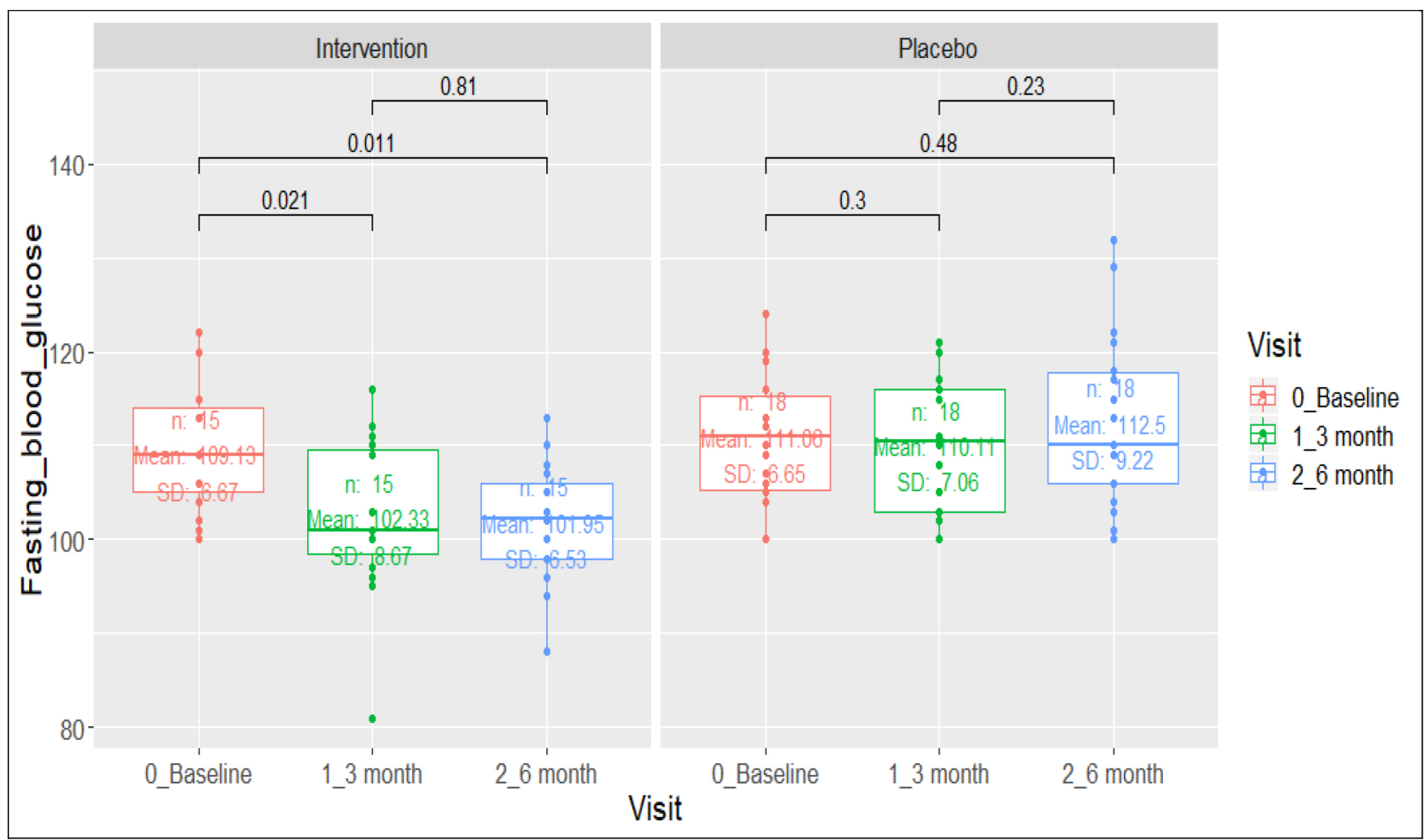

Figure 3. Comparison of Fasting Blood Glucose ( $>=100 \mathrm{mg} / \mathrm{dl})$ in Prediabetes Group 
Alben Sigamani (2019) A Polyherbal Indian System of Medicine (Ayush) Preparation for Optimization of Glycemic Control in Newly Diagnosed Type 2 Diabetes and Prediabetes; A Multicenter, Randomised, Double-Blind, Placebo-Controlled Trial

Table 1. Characteristics of the study participants at baseline level.

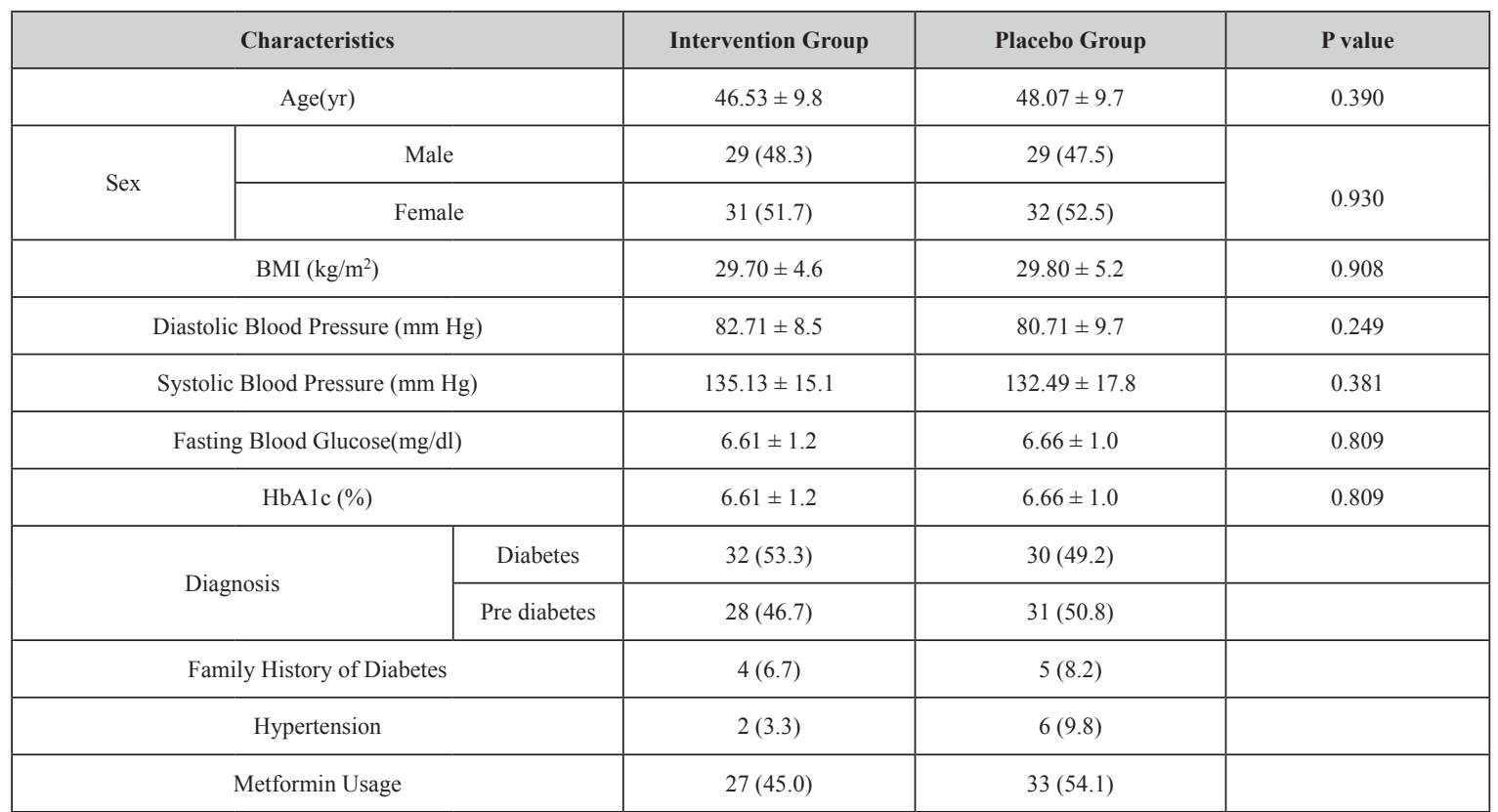

All the participants have Asian ethnicity.

None of the participants have used oral hypoglycemic agents and insulin.

Table 2. Comparison of the mean FBG and $\mathrm{HbAlc}$ before and after the intervention among the intervention and the placebo groups.

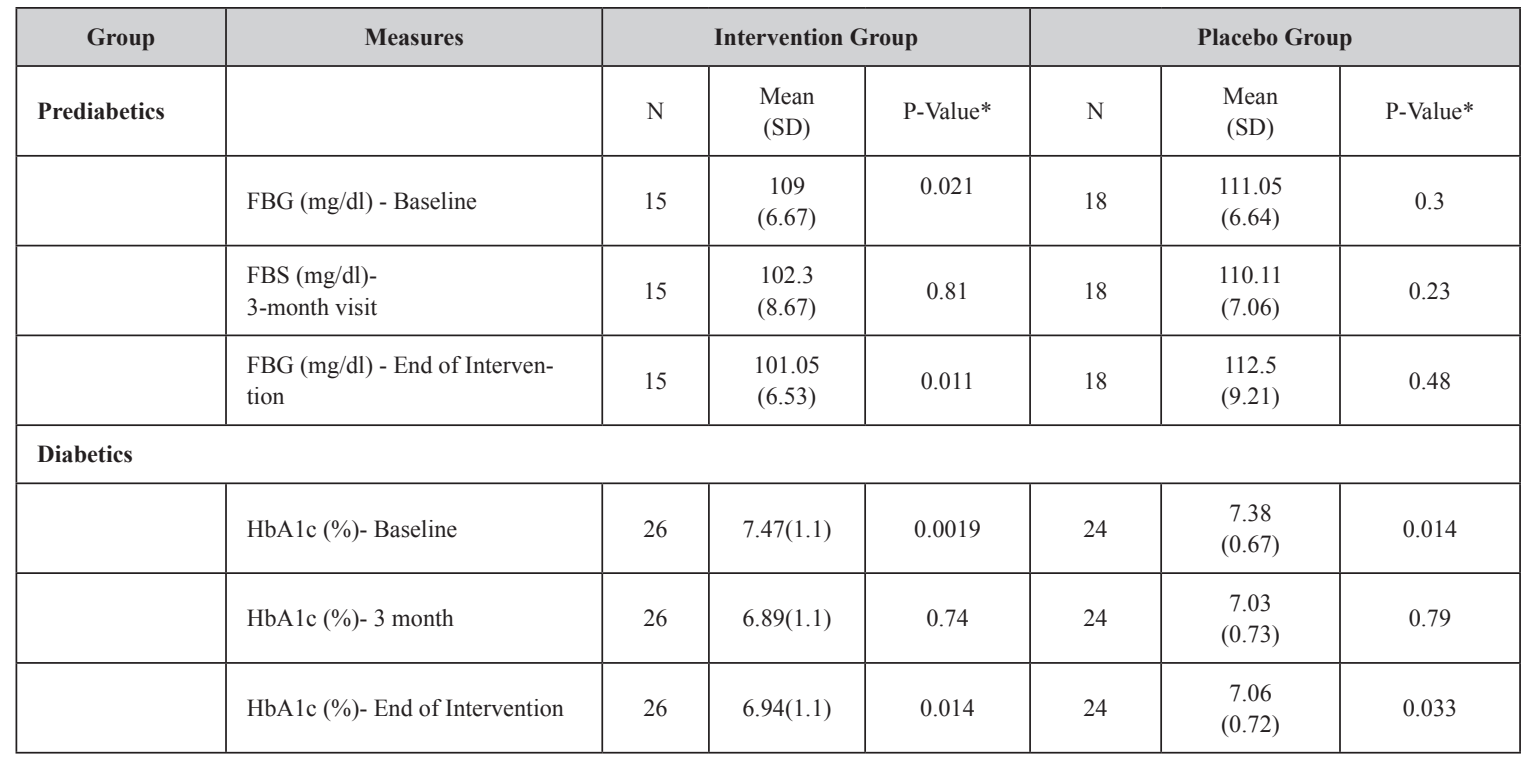

*p-value was calculated based on Paired t-test

Table 3. Fasting Blood Glucose at Day 180 for Prediabetes

\begin{tabular}{|c|c|c|c|c|c|c|}
\hline \multirow{3}{*}{$\begin{array}{c}\text { End of Study Treatment Visit FPG } \\
\text { (Prediabetes) }\end{array}$} & \multicolumn{4}{|c|}{ Group } & \multirow{2}{*}{\multicolumn{2}{|c|}{ Total }} \\
\hline & \multicolumn{2}{|c|}{ Intervention } & \multicolumn{2}{|c|}{ Placebo } & & \\
\hline & Count & $\%$ & Count & $\%$ & Count & $\%$ \\
\hline$<100$ & 13 & 52.0 & 4 & 15.4 & 17 & 33.3 \\
\hline$>100$ & 12 & 48.0 & 22 & 84.6 & 34 & 66.7 \\
\hline Total & 25 & 100.0 & 26 & 100.0 & 51 & 100.0 \\
\hline
\end{tabular}

$p=0.008$ 
Alben Sigamani (2019) A Polyherbal Indian System of Medicine (Ayush) Preparation for Optimization of Glycemic Control in Newly Diagnosed Type 2 Diabetes and Prediabetes; A Multicenter, Randomised, Double-Blind, Placebo-Controlled Trial

\section{Safety}

All participants were monitored for Adverse Events (AE's) and Serious Adverse Events (SAE's) throughout the trial. The distribution of unsolicited AE's who were administered the active treatment i.e. diabetic participants who were on metformin was $4(14.81 \%)$ of 27 and prediabetic was $3(12 \%)$ of 25 .

The distribution of unsolicited AE's who were administered the placebo treatment i.e. diabetic participants who were on metformin was $3(11.11 \%)$ of 27 and prediabetic was $2(7.69 \%)$ of 26 . The AE's reported are Gastrointestinal (GIT) symptoms and dizziness in the diabetic participants and weakness, joint pains and headache in the prediabetic participants in the active and placebo groups. No significant between-group differences were identified $(\mathrm{p}=1.0)$.

Using the Diabetes Trial and Safety of Metformin [9], as a reference for safety monitoring, we find that subjects who are diabetic and on the medication of Metformin have a similar AE's reported i.e. Gastrointestinal (GIT) symptoms (28\% in Metformin versus $16 \%$ in Placebo), Self-reported GIT problems (9.5\% in Metformin compared to $1.1 \%$ in Placebo), Anaemia more common in subjects taking metformin (50 subjects) versus 38 subjects in Placebo group.

\section{Discussion}

India is home to 75 million people suffering from diabetes and an equally large percentage of those who have prediabetes [10,11]. Our trial described in this report, used a randomised placebo controlled double blind study to analyze the effects of a polyherbal formulation in bringing about an improvement in glycemic control. Glycated hemoglobin is widely regarded as a standard for monitoring glycemic control in diabetes management. It reflects the mean plasma glucose over period of 120 days, and comprises of the level of blood sugar control in the last 25 days prior to the test. Its fasting value is reflection of the average plasma sugar in the fasting state and also the amplitude of the glycemic spikes occurring post prandial.

The trial participants diagnosed with diabetes were allowed to be on metformin which has an effect of lowering hyperglycemia through reduction of hepatic glucose production and decreased glucose absorption from the intestines. Subjects who received sugar balance along with metformin showed better glycemic control $\left(\mathrm{HbA}_{1 \mathrm{c}}<0.5 \%\right)$ compared to those only on metformin. The polyherb did not decrease fasting glycaemia when compared to metformin alone. But among the prediabetes cohort, those who were only on sugar balance achieved their target lowering of fasting glycaemia better than the placebo.

Sugar Balance $^{\circledR}(\mathrm{SB})$ contains 3 whole herbs, Coccinia indica, Bougainvillea spectabilis and Madagascar periwinkle or Sadabahar. Coccinia indica has long been traditionally used in Ayurveda for diabetes care and has been studied in vivo extensively for its hypoglycemic effects ${ }^{10}$. Phytoconstituents in the plant like polyprenol, steroidalsaponins, and cucurbitane-type triterpenoids are known to intercept glucose metabolism [13]. Bougainvillea spectabilis has also shown antidiabetic properties via increasing glucose-6phosphate dehydrogenase activity and promoting glucose uptake [14]. Madagascar perinwinkle usage for diabetes comes from the traditional period though its efficacy today has been proven through phytochemical analysis and in vivo research [15]. For example, four alkaloids identified in the plant induce significantly high glucose uptake in pancreatic $\beta$-TC6 cells [16].

There is a limited clinical trial information on hypoglycemic effects of individual components of Sugar Balance formulation in Prediabetes and Diabetes patients. Furthermore, proper randomised controlled trial is lacking with all of the polyherbs in combination. Coccina Indica and D-Pinitol isolated from Bougainbellia has been tested for hypoglycemic effect in Humans [12, 17-19]. The Vinca rosea extract is known to have anti-inflammatory properties and hypoglycemic effect in animal models but hypoglycemic action is not tested in clinical trial.

According to a popular textbook published by a Clinical Pharmacologist, Dr. Narendra Singh the potential mechanism of action of Sugar Balance are delayed absorption of glucose, regulation of glucose metabolism as well as improvement in glucose tolerance test [20].

The strengths of this trial is the mimicking of current practice of treating new onset type 2 diabetes with biguanides and prediabetes with just lifestyle and diet. This randomised double-blind placebocontrolled trial, has clinical relevance by proving improvement in glycated hemoglobin among those with type 2 diabetes and increasing the proportion of achieving fasting glycemic control in 6 months. Unlike other trials that have tested the effects of a herbal preparation, this trial tested the intervention along with a standard of care regimen of metformin. The synergistic effect of combining the polyherb with metformin did not increase the risk of hypoglycemia (none reported in the trial). It is important for add-on therapies to help improve glycemic control and not increase the risk of hypoglycemia or cause significant drop in fasting blood sugar. This has been shown to improve long term benefits in diabetes and improves compliance to therapy.

Limitations of this study include the relatively short duration (24 weeks). A longer study might have provided the long-term effect of the combination. However, guidelines limit placebo-controlled trials to 6 months duration. The treatment effect was not significantly different from the placebo group in patients with type 2 diabetes. Probable cause will have been physician preference and patient preference in dose of metformin used through the trial. Also, the lower baseline parameters compared to most other trials could have mitigated the probable greater fall in $\mathrm{HbA}_{1 \mathrm{c}}$ in a short period. Further studies in this population can be done for seeing efficacy in combination with other oral hypoglycemic agents and also those with moderate to poor control of diabetes.

\section{Conclusion}

In conclusion, the result of the present study suggest that Sugar Balance has a potential hypoglycemic action which increases insulin production and decreases the amount of glucose in the blood, and thus could represent a possible preventative treatment strategy for prediabetes as well as new onset type 2 diabetes patients.

\section{Financial Disclosure}

Organic India Pvt Ltd are the sponsors of the study, they have funded and contributed to all aspects of the study, and were not involved 
Alben Sigamani (2019) A Polyherbal Indian System of Medicine (Ayush) Preparation for Optimization of Glycemic Control in Newly Diagnosed

Type 2 Diabetes and Prediabetes; A Multicenter, Randomised, Double-Blind, Placebo-Controlled Trial

in any stage of the conduct and analysis of this study, including study design, data collection, data analysis, data interpretation, and writing of the report. All authors had full access to all the data in the study and had final responsibility for the decision to submit for publication.

\section{Conflicting Interest}

The corresponding author declares that he had full access to the data and complete control on the analysis and publication of its results. He declares having received grants from organic India to carry out this project. He or his family members do not have any financial holding with the company. Other authors except Dr Subramanian Kanan, did receive remuneration from this grant provided by Organic India. Haleh and Leva has no conflict of interest to declare.

\section{References}

1. International Diabetes Federation IDF (2017) Diabetes Atlas, 8 edn. International Diabetes Federation: Brussels, Belgium, 2017.

2. Sathasivampillai SV, Rajamanoharan PRS, Munday M, Heinrich M (2017) Plants used to treat diabetes in Sri Lankan Siddha Medicine - An ethnopharmacological review of historical and modern sources. J Ethnopharmacol 198: 531-599. [crossref]

3. Vos T (2016) Global, regional, and national incidence, prevalence, and years lived with disability for 310 diseases and injuries, 1990-2015. The Lancet 1545-1602.

4. Kaveeshwar SA, Cornwall J (2014) The current state of diabetes mellitus in India. Australas Med J 7: 45-48. [crossref]

5. Ezzati PM (2016) Worldwide trends in diabetes since 1980: a pooled analysis of 751 population-based studies with $4 \bullet 4$ million participants. The Lancet $1513-1530$.

6. Frank NJ (2010) Ayurveda: A Comprehensive Guide to Traditional Indian Medicine for the West. Rowman \& Littlefield Publishers.

7. Barnes P, Bloom B, Nahin R, \& National Center for Health Statistics (2008) Complementary and alternative medicine use among adults and children: United States, 2007 (National health statistics reports; no. 12). Hyattsville, MD: U.S. Dept. of Health and Human Services, Centers for Disease Control and Prevention, National Center for Health Statistics.

8. Kessler, Wischnewsky, Michalsen, Eisenmann, \& Melzer (2013) Ayurveda: Between Religion, Spirituality, and Medicine. Evid Based Complement Alternat Med 2013, 11.

9. Bray G, Edelstein S, Grandall J, Aroda V, Franks P (2012) Long-Term Safety, Tolerability, and Weight Loss Associated With Metformin in the Diabetes Prevention Program Outcomes Study. Diabetes Care 35: 731-737.

10. Anjana RM, Deepa M, Pradeepa R, Mahanta J, Narain K, Das HK, et al. Prevalence of diabetes and prediabetes in 15 states of India: results from the ICMR-INDIAB population-based cross-sectional study. The Lancet Diabetes \& Endocrinology. 2017;5: 585. [crossref]

11. Dasappa H, Fathima FN, Prabhakar R, Sarin S. Prevalence of diabetes and prediabetes and assessments of their risk factors in urban slums of Bangalore. J Family Med Prim Care. 2015;4(3): 399-404. [crossref]

12. Azad Khan AK, Akhtar S, Mahtab H (1979) Coccinia indica in the treatment of patients with diabetes mellitus. Bangladesh Med Res Counc Bull 5: 60-66. [crossref]

13. Kaushik U, Aeri V, Showkat RM, Ali M (2017) Cucurbitane-Type Triterpenoids from the Blood Glucose-Lowering Extracts of Coccinia indica and Momordica balsamina Fruits. Pharmacogn Mag 13: 115-121.

14. Bhat M, Kothiwale SK, Tirmale AR, Bhargava SY, Joshi BN (2011) Antidiabetic Properties of Azardiracta indica and Bougainvillea spectabilis: In Vivo Studies in Murine Diabetes Model. Evid Based Complement Alternat Med 2011: 561625.

15. Das S, Sharangi AB (2017) Madagascar periwinkle (Catharanthus roseus L.): Diverse medicinal and therapeutic benefits to humankind. J Pharmacogn Phytochem 6: 1695-701.

16. Tiong SH, Looi CY, Hazni H, Arya A, Paydar M, et al. (2013) Antidiabetic and antioxidant properties of alkaloids from Catharanthus roseus (L.) G. Don. Molecules 18: 9770-9784. [crossref]

17. Kuriyan R, Rajendran R, Bantwal G, Kurpad A V (2008) Effect of Supplementation of Coccinia cordifolia Extract on Newly Detected Diabetic Patients. Diabetes Care 31: $216-220$.

18. Kim HJ, Park KS, Lee SK, et al. (2012) Effects of Pinitol on Glycemic Control, Insulin Resistance and Adipocytokine Levels in Patients with Type 2 Diabetes Mellitus. Ann Nutr Metab 60: 1-5.
19. Hernández-Mijares A, Bañuls C, Peris JE, et al. (2013) A single acute dose of pinitol from a naturally-occurring food ingredient decreases hyperglycaemia and circulating insulin levels in healthy subjects. Food Chem 141: 1267-72.

20. Singh N, Gilca M (2010) Herbal medicine. Saarbrucken, Germany: Lambert Academic Pub.

\section{Citation:}

Alben Sigamani, Sanjaya Chauhan, Vikneswaran G, Sindhu N, Anju Joseph, Arun Kumar, Padma KG, Sandeep Kumar Gupta, Shashank Tiwari, Subramanian Kannan, Haleh Roohi, Leva Samimi, Prathipati Philip and Chandrakala Pidathala (2019)A Polyherbal Indian System of Medicine (Ayush) Preparation for Optimization of Glycemic Control in Newly Diagnosed Type 2 Diabetes and Prediabetes; A Multicenter, Randomised, Double-Blind, Placebo-Controlled Trial. Endocrinol Diabetes Metab J Volume 3(2): 1-8. 